\title{
Article
}

\section{Microporous Polyimides from Ladder Diamines Synthesized by Facile Catalytic Arene-Norbornene Annulation as High-Performance Membranes for Gas Separation}

Mahmoud A. Abdulhamid, Holden W. H. Lai, Yingge Wang, Zexin Jin, Yew Chin Teo, Xiaohua Ma, Ingo Pinnau, and Yan Xia

Chem. Mater., Just Accepted Manuscript • DOI: 10.1021/acs.chemmater.8b05359 • Publication Date (Web): 06 Feb 2019

Downloaded from http://pubs.acs.org on February 20, 2019

\section{Just Accepted}

"Just Accepted" manuscripts have been peer-reviewed and accepted for publication. They are posted online prior to technical editing, formatting for publication and author proofing. The American Chemical Society provides "Just Accepted" as a service to the research community to expedite the dissemination of scientific material as soon as possible after acceptance. "Just Accepted" manuscripts appear in full in PDF format accompanied by an HTML abstract. "Just Accepted" manuscripts have been fully peer reviewed, but should not be considered the official version of record. They are citable by the Digital Object Identifier (DOI®). "Just Accepted" is an optional service offered to authors. Therefore, the "Just Accepted" Web site may not include all articles that will be published in the journal. After a manuscript is technically edited and formatted, it will be removed from the "Just Accepted" Web site and published as an ASAP article. Note that technical editing may introduce minor changes to the manuscript text and/or graphics which could affect content, and all legal disclaimers and ethical guidelines that apply to the journal pertain. ACS cannot be held responsible for errors or consequences arising from the use of information contained in these "Just Accepted" manuscripts. 


\title{
Microporous Polyimides from Ladder Diamines Synthesized by Fac- ile Catalytic Arene-Norbornene Annulation as High-Performance Membranes for Gas Separation
}

\author{
Mahmoud A. Abdulhamid ${ }^{\dagger,}$, , Holden W. H. Lai ${ }^{\ddagger}$, ,, Yingge Wang ${ }^{\dagger}$, Zexin Jin ${ }^{\ddagger}$, Yew Chin Teo ${ }^{\ddagger}$, \\ Xiaohua $\mathrm{Ma}^{\dagger}$, Ingo Pinnau ${ }^{\dagger, *}$, and Yan $\mathrm{Xia}^{\ddagger, *}$ \\ †Functional Polymer Membranes Group, Advanced Membranes and Porous Materials Center, Division of Physical \\ Sciences, King Abdullah University of Science and Technology (KAUST), Thuwal 23955-6900, KSA. \\ ‡Department of Chemistry, Stanford University, Stanford, California 94305, United States.
}

\begin{abstract}
We synthesized a series of rigid ladder-type diamines from readily available bromoanilines and norbornadiene in one step using facile catalytic arene-norbornene annulation (CANAL). Polycondensation of CANAL ladder diamines with 4,4'-(hexafluoroisopropylidene) diphthalic anhydride led to a series of microporous polyimides with different degrees of rotational freedom around the imide linkages. CANAL-PIs exhibited good solubility in a wide range of organic solvents, high thermal stability with decomposition temperature above $450^{\circ} \mathrm{C}$, high Brunauer-Emmett-Teller surface areas of $\sim 200$ - $530 \mathrm{~m}^{2} \mathrm{~g}^{-1}$, and abundant micropore volume with variable pore size distributions. Mechanically robust membranes can be easily formed from CANAL-PIs and gave high gas permeabilities and moderate gas-pair selectivities. CANAL-PIs had higher permeability and similar permselectivity to analogous PIs synthesized from Tröger's base and carbocyclic Tröger's base diamines under identical test conditions. CANAL-PIs also exhibited relatively slow physical aging. These favorable properties and performance make microporous polymers based on CANAL ladder motifs promising membrane materials for gas separation.
\end{abstract}

\section{INTRODUCTION}

Soluble microporous polymers have emerged as an important class of processable membrane materials for gas separation, which have stringent requirements for the physical, transport, and processing properties of polymers. ${ }^{1-6}$ In order to achieve microporosity while remaining soluble and thus solution-processable, the polymers must contain a high density of rigid yet contorted spirocyclic and/or ladder molecular motifs. ${ }^{17-9}$ The best known class of such polymers is termed polymers of intrinsic microporosity (PIMs). ${ }^{1}$ Commonly used rigid and contorted molecular structures for PIMs and other microporous polymers are limited to a few building blocks, such as triptycene, ${ }^{10-17}$ spirobisindane, ${ }^{18-21}$ spirobifluorene, ${ }^{22-25}$ and Tröger's base. ${ }^{20,} 26-30$ This is largely due to the limited chemistry for efficient and versatile synthesis of rigid ladder molecular motifs. Additionally, functionalized ladder motifs often require multistep synthesis. ${ }^{13,}$ 17, 23,29 Rational design of new polymer membranes for gas separation necessitates the understanding of how different molecular motifs affect the polymer's chain packing and transport properties. Therefore, it is highly desirable to develop new contorted ladder- or pseudoladder polymers and compare the physical parameters and separation performance of polymers consisting of a diverse array of motifs.

We recently reported the synthesis of rigid ladder polymers with norbornyl benzocyclobutene backbones via efficient catalytic arene-norbornene annulation (CANAL) from readily available dibromoarenes and norbornadiene or dinorbornenes as monomers. ${ }^{31-33}$ Rigid and dense contortion in the backbones of CANAL ladder polymers led to high surface area and tunable microporosity, features that are desirable for highly permeable and selective gas separation membranes. CANAL polymers also exhibited excellent thermal stability, despite the high density of strained four-membered rings. ${ }^{3}$ However, the CANAL ladder polymers in our original reports were mechanically fragile and unable to form self-standing membranes. We envisioned that efficient and versatile CANAL chemistry can alternatively be used to synthesize ladder motifs as monomers for other types of polymers, such as polyimides (PIs). PIs generally exhibit robust mechanical properties, ${ }^{34-36}$ and the constituent CANAL ladder repeat units are expected to generate microporosity.

Herein, we report the facile synthesis of a series of CANAL ladder diamines with a norbornyl bis-benzocyclobutene $\left(\mathrm{N}_{2} \mathrm{BC}\right)$ motif from readily available bromoanilines and norbornadiene, and their polycondensation with dianhydride to form polyimides of intrinsic microporosity (PIM-PIs). These CANAL-PIs exhibited remarkable thermal and mechanical properties as well as promising transport properties for gas separation. The simple and efficient CANAL reaction will allow the synthesis of structurally, conformationally, and functionally diverse microporous PIs, enabling further understanding of the structure-property relationships for microporous polymer membranes. 


\section{RESULTS AND DISCUSSION}

Synthesis. We sought to synthesize a series of CANAL diamines with and without methyl groups ortho to the amines, which can lead to different degrees of rotational freedom for the imide linkage in the resulting PIs. We first attempted the synthesis of CANAL diamines by reaction of 2 equiv. of $4^{-}$ bromo-2-methylaniline 1 or 4-bromo-2,6-dimethylaniline 2 with 1 equiv. norbornadiene (NBD) in the presence of $1 \mathrm{~mol} \%$ $\mathrm{Pd}(\mathrm{OAc})_{2}$ and $2 \mathrm{~mol} \% \mathrm{PPh}_{3}$ in toluene at $115^{\circ} \mathrm{C}$, the standard condition we previously reported. $3^{11}$ However, the reaction was very sluggish with $<10 \%$ conversion of bromoanilines after 24 $\mathrm{h}$, possibly due to the intermolecular coordination of amino groups. Increasing the temperature to $150^{\circ} \mathrm{C}$ and changing the solvent to 1,4-dioxane led to complete consumption of starting materials and $\sim 30 \%$ yields of the CANAL diamines, CANAL-1$\mathrm{MeNH}_{2}$ and CANAL-2- $\mathrm{Me}_{2} \mathrm{NH}_{2}$, presumably in syn and anti regioisomers (Scheme 1). To further improve the yields of CANAL diamines, we reasoned that a noncoordinating substituent ortho to the bromide may promote the formation of palladacycle, an important intermediate in the catalytic cycle, and its reductive elimination to form the desired product (Scheme $\mathrm{S}_{1}$ ). ${ }^{11,38}$ Therefore, we used bromoaniline 2' with a methyl group ortho to the bromide as the substrate. Reactions of $\mathbf{2}$ and $\mathbf{2}$ yielded the same diamine. Remarkably, z' gave significantly improved yields of $>70 \%$ (Scheme 1 ). Using $4^{-}$ bromo-3-methylaniline 3, we also synthesized CANAL-3$\mathrm{MeNH}_{2}$ without substituents ortho to the amino group in $81 \%$ yield. Notably, CANAL reactions using the bromoanilines with a methyl group ortho to the bromide can be carried out on the gram scale with simple column chromatography to yield pure ladder-shaped diamines.

Due to the selective formation of exo-isomer in CANAL as we reported previously, ${ }^{31}$ the $\mathrm{N}_{2} \mathrm{BC}$ motif is $\mathrm{W}$-shaped, as clearly revealed by the crystal structure of a model compound (CANAL-model, Figure. 1, Table $\mathrm{S}$ ). The crystal structure also revealed a $119^{\circ}$ angle between the benzocyclobutene plane and the norbornyl unit (Figure $\mathrm{lb}$ ). Interestingly, the four-membered rings showed a trapezoidal shape with a significantly elongated C-C bond of $1.6 \AA$ that is fused with the norbornyl unit and a slightly distorted phenyl rings, due to ring strain.

We next synthesized CANAL-PIs by reacting the CANAL diamines (used as a mixture of regioisomers) with a commonly used dianhydride, 4,4'-(hexafluoroisopropylidene) diphthalic anhydride (6FDA) (Scheme 2), in the presence of a catalytic amount of isoquinoline in $m$-cresol at $200{ }^{\circ} \mathrm{C}$ for $4 \mathrm{~h}$ under a continuous $\mathrm{N}_{2}$ flow. ${ }^{1} \mathrm{H}$ NMR spectroscopy of the isolated polymers showed no signals downfield of $10 \mathrm{ppm}$, indicating complete imidization (Figures $\mathrm{S}_{3}, \mathrm{~S} 6, \mathrm{~S} 9$ ). Observation of all the expected signals from the $\mathrm{N}_{2} \mathrm{BC}$ motifs suggested the preservation of the ladder repeat units in the PIs. The characteristic IR absorption bands of the imide group were observed at 1774, $1711 \mathrm{~cm}^{-1}$ (imide asymmetric and symmetric $\mathrm{C}=\mathrm{O}$ stretching, respectively), and $1361 \mathrm{~cm}^{-1}$ (C-N, stretching frequency) (Figure S1o). The CANAL-PIs exhibited good solubility in a wide range of common organic solvents as listed in Table S2. Gel permeation chromatography (GPC) analysis of the CANALPIs using polystyrene standard calibration showed high $M_{\mathrm{n}}$ in the range of $27-92 \mathrm{~kg} \mathrm{~mol}^{-1}$ and dispersities ( $\left({ }^{\prime} \mathrm{s}\right)$ of 1.4-2 (Table 1).
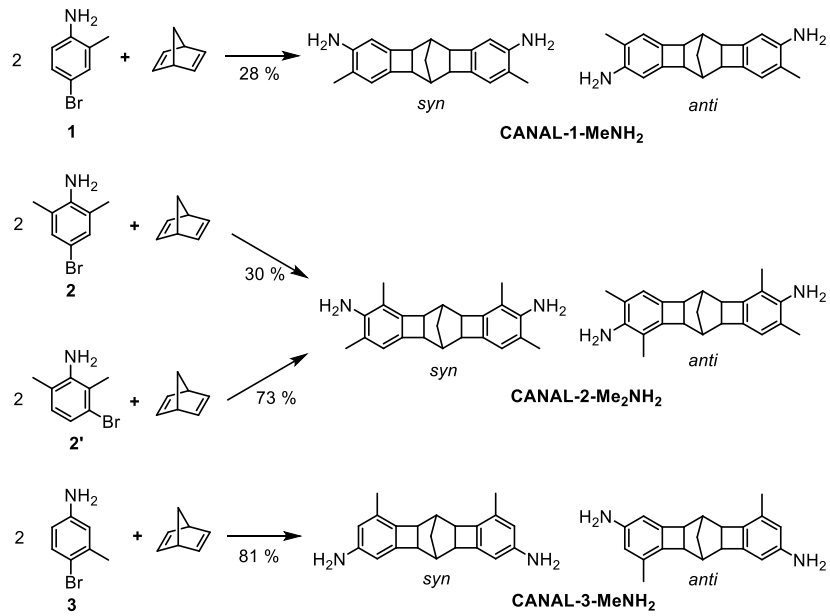

Scheme 1. Synthesis of CANAL diamines. Reaction conditions: 1 equiv. bromoaniline, 0.5 equiv. nobornadiene, 1 $\mathrm{mol} \% \mathrm{Pd}(\mathrm{OAc})_{2}$, 2 mol\% $\mathrm{PPh}_{3}$, 1 equiv. $\mathrm{Cs}_{2} \mathrm{CO}_{3}$, 1,4-dioxane, $150^{\circ} \mathrm{C}$. (a)

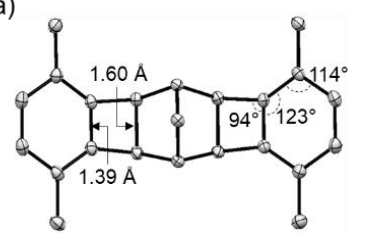

(b)

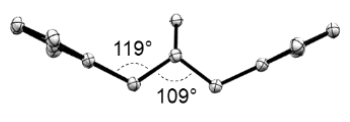

Figure 1. X-ray crystal structure of a CANAL model compound showing a $\mathrm{W}$-shape in (a) top and (b) side view. Hydrogen atoms are omitted for clarity.
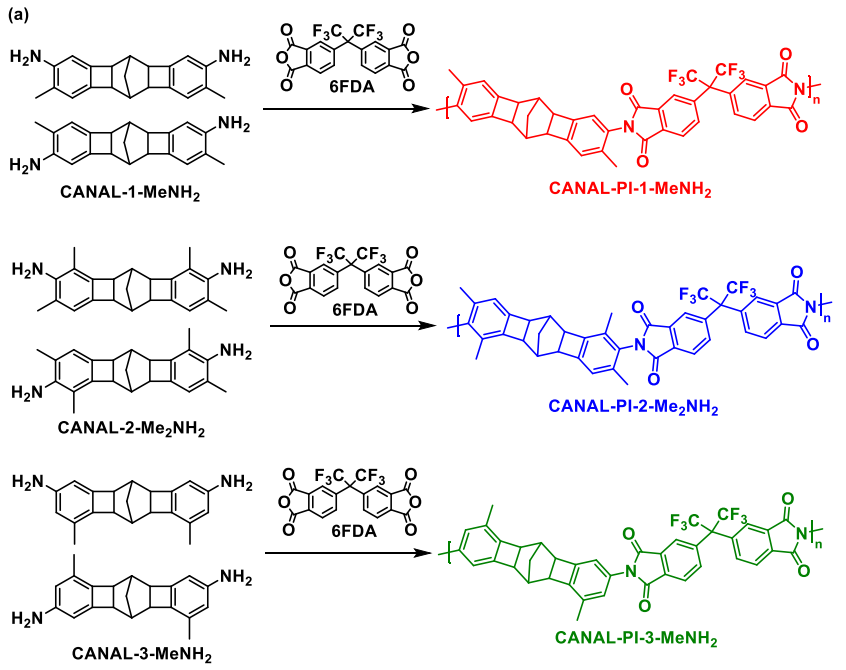

(b)
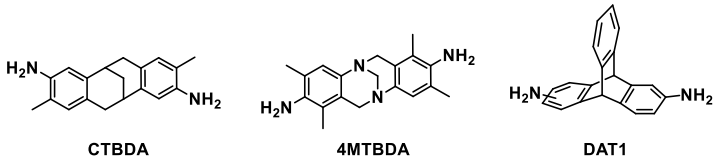

Scheme 2. (a) Synthesis of CANAL-PIs (only the anti isomers of diamines are shown in the structures of the PIs for clarity). Reaction conditions: isoquinoline, $\mathrm{m}$-cresol, $200^{\circ} \mathrm{C}$. (b) Structures of previously reported ladder diamines that were used to synthesize PIM-PIs. 
Thermal and Mechanical Properties. CANAL-PIs showed remarkably high thermal stability with decomposition temperatures exceeding $45^{\circ} \mathrm{C}$ (Figure S11 and Table 1). Similar to CANAL ladder polymers, no glass transition was detected in the CANAL-PIs by differential scattering calorimetry (DSC) up to $350^{\circ} \mathrm{C}$. Homogenous, transparent, and mechanically robust membranes of the CANAL-PIs can be easily obtained by casting their chloroform solutions in circular and flat Petri dishes. The film thickness was controlled to be $40-55 \mu \mathrm{m}$. The films were highly flexible (Figure 2) and allowed for easy processing. CANAL-PIs showed excellent mechanical performance with high Young's modulus (0.95-1.1 GPa) and tensile strength (24-50 MPa) (Figure $S_{12}$ and Table $S_{3}$ ).

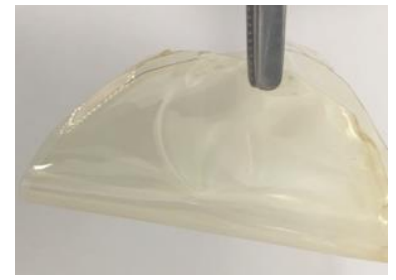

Figure 2. Photograph of a representative CANAL-PI membrane showing high flexibility.

Table 1. Properties of CANAL-PIs.

\begin{tabular}{|c|c|c|c|c|c|}
\hline Polymer & $\begin{array}{l}M_{\mathrm{w}}^{\mathrm{a}} \\
\left(\mathrm{g} \mathrm{mol}^{-}\right. \\
\left.{ }^{1}\right)\end{array}$ & $\begin{array}{l}M_{\mathrm{n}}{ }^{\mathrm{a}} \\
(\mathrm{g} \\
\left.\mathrm{mol}^{-1}\right)\end{array}$ & $\oplus^{\mathrm{a}}$ & $\begin{array}{l}\mathrm{T}_{\mathrm{d}, 5 \%} \\
\mathrm{~b} \\
\left({ }^{\circ} \mathrm{C}\right)\end{array}$ & $\begin{array}{l}\text { Den- } \\
\text { sity }{ }^{\mathrm{c}} \\
(\mathrm{g} \mathrm{cm} \\
\text { 3) }\end{array}$ \\
\hline $\begin{array}{l}\text { CANAL-PI- } \\
\text { 1-MeNH }\end{array}$ & 55,800 & 27,000 & 2.0 & 488 & 1.22 \\
\hline $\begin{array}{l}\text { CANAL-PI- } \\
2-\mathrm{Me}_{2} \mathrm{NH}_{2}\end{array}$ & 175,800 & 91,500 & 1.9 & 480 & 1.17 \\
\hline $\begin{array}{l}\text { CANAL-PI- } \\
3-\mathrm{MeNH}_{2}\end{array}$ & 67,700 & 50,000 & 1.4 & 451 & 1.20 \\
\hline
\end{tabular}

Surface Area Characterizations. When incorporated into PIs, the $\mathrm{N}_{2} \mathrm{BC}$ motif remained effective at preventing dense chain packing. CANAL-PIs exhibited Brunauer-Emmett-Teller (BET) surface areas of $200-530 \mathrm{~m}^{2} \mathrm{~g}^{-1}$, based on $\mathrm{N}_{2}$ sorption isotherms at $77 \mathrm{~K}$ (Figure 3). Ortho substitution on the aryl imide is expected to restrict the $\mathrm{C}-\mathrm{N}$ bond rotation in the backbones of PIs, thus leading to higher intrachain rigidity and more frustrated chain packing. ${ }^{36}$ Therefore, CANAL-PI-2- $\mathrm{Me}_{2} \mathrm{NH}_{2}$, which has two methyl substituents ortho to the imide linkage, had a much higher BET surface area $\left(533 \mathrm{~m}^{2} \mathrm{~g}^{-1}\right)$ than the other two PIs with only one or no methyl substituent ortho to the imide linkage (both $\sim 200 \mathrm{~m}^{2} \mathrm{~g}^{-1}$ ). Therefore, the combination of restricted rotation of the imide linkage and rigid CANAL motifs led to the high surface area of CANAL-PI-2- $\mathrm{Me}_{2} \mathrm{NH}_{2}$ that is comparable to those of CANAL ladder polymers. ${ }^{31-33}$

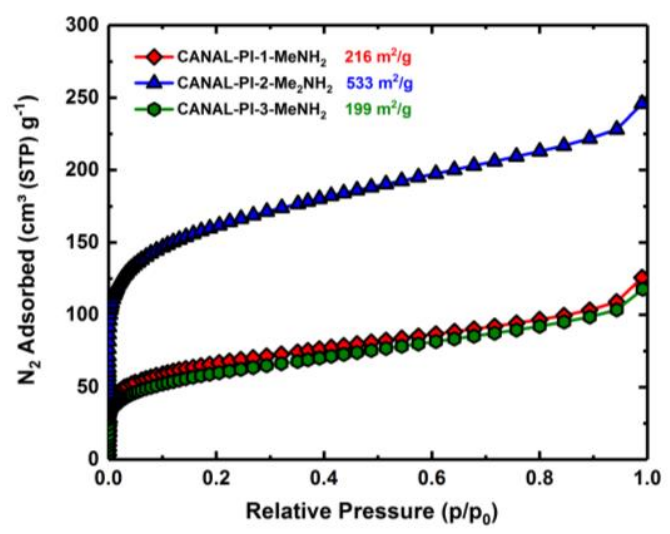

Figure 3. N2 sorption isotherms of CANAL-PIs at $77 \mathrm{~K}$.

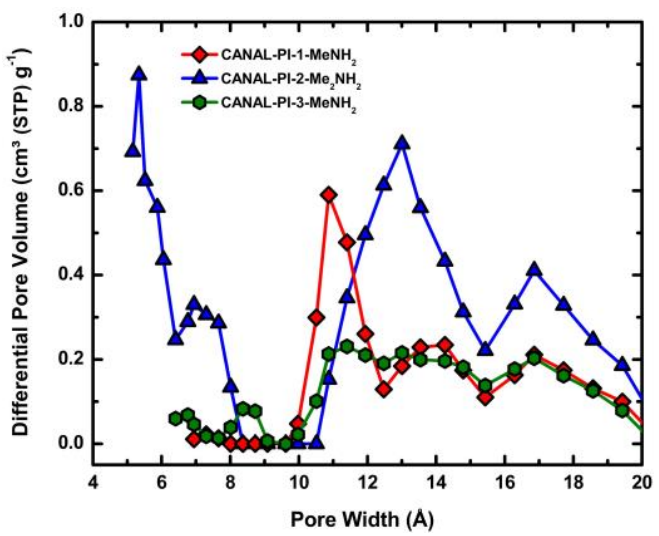

Figure 4. NLDFT-derived pore size distributions of CANAL-PIs.

To further elucidate the structural differences between the CANAL-PIs, we also estimated their micropore size distributions using their ultralow-pressure $\mathrm{N}_{2}$ gas sorption data by nonlocal density functional theory (NLDFT) calculations as shown in Figure 4. All the polymers contained a large fraction of micropores in the range of $8-20 \AA$. The total volume of micropores followed the order of CANAL$\mathrm{PI}-2-\mathrm{Me}_{2} \mathrm{NH}_{2}>$ CANAL-PI-1-MeNH $\mathrm{H}_{2}>$ CANAL-PI-3$\mathrm{MeNH}_{2}$. The region of ultramicroporosity $(<7 \AA)$ was only accessible by $\mathrm{N}_{2}$ sorption at $77 \mathrm{~K}$ for CANAL-PI-2- $\mathrm{Me}_{2} \mathrm{NH}_{2}$ with the highest BET surface area, presumably due to the denser chain packing of the other two CANAL-PIs. 

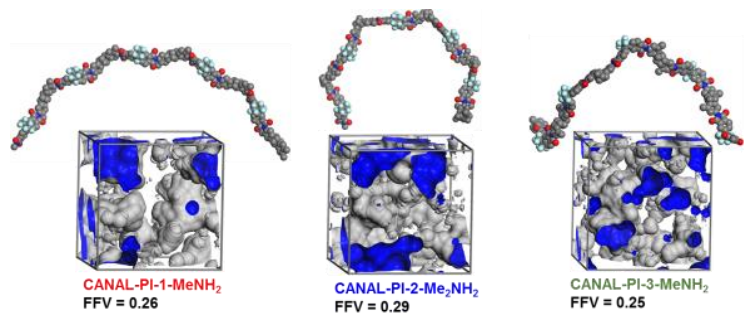

Figure 5. Molecular dynamics simulation of CANAL-PIs in an amorphous cell with calculated fractional free volume values illustrated in blue.

Consistent with the BET surface areas, molecular dynamics simulation showed that CANAL-PI-2- $\mathrm{Me}_{2} \mathrm{NH}_{2}$ exhibited the highest fractional free volume (FFV) of 0.29 , followed by CANAL-PI-1-MeNH${ }_{2}$ and CANAL-PI-3-MeNH with FFV of 0.26 and 0.25 , respectively (Figure 5).

Gas Permeation Properties. Using the mechanically robust CANAL-PI membranes, we measured the permeability of light gases, including $\mathrm{H}_{2}, \mathrm{~N}_{2}, \mathrm{O}_{2}, \mathrm{CH}_{4}$, and $\mathrm{CO}_{2}$. The permeability qualitatively followed the same trend as the BET surface areas in this series of CANAL-PIs. In general, the polymers displayed high permeability with moderate gas-pair selectivity (Table 2). For example, the $\mathrm{O}_{2}$ permeability values of CANAL-PI-1-MeNH${ }_{2}$, CANAL-PI-2- $\mathrm{Me}_{2} \mathrm{NH}_{2}$ and CANAL-PI-3-MeNH${ }_{2}$ were 81, 319, and 33 barrer, respectively (1 barrer $=10^{-10} \mathrm{~cm}^{3} \mathrm{~cm} \mathrm{~cm}^{-2} \mathrm{~s}^{-1} \mathrm{cmHg}^{-1}$ ). The presence of methyl groups ortho to the imide linkage significantly increased permeability but lowered permselectivity.

Permselectivity consists of diffusivity selectivity and solubility selectivity. To better understand the observed permselectivity, we calculated diffusion coefficients of different gases for CANAL-PIs using the time lag equation and determined the solubility coefficients by assuming the solution diffusion model $\mathrm{P}=\mathrm{DS}$ (Table $\mathrm{S}_{4}$ ). Both the solution and diffusion coefficients of CANAL-PIs are one to two orders of magnitude higher than those of "nonporous" PIs. $35-36$ Concomitant with the increase in permeability for CANAL-PIs is the increase in diffusion coefficient with simultaneous decrease in diffusivity selectivity (Table $\mathrm{S}_{5}$ ). The order of permeability for gases in CANAL-PI-1-MeNH and CANAL-PI-3-MeNH${ }_{2}$ followed the same trend as the kinetic diameters of gases $\left(\mathrm{P}_{\mathrm{H}_{2}}>\mathrm{P}_{\mathrm{CO}_{2}}>\mathrm{P}_{\mathrm{O}_{2}}>\mathrm{P}_{\mathrm{N}_{2}}>\mathrm{P}_{\mathrm{CH}_{4}}\right)$. Interestingly, CANAL-PI-2- $\mathrm{Me}_{2} \mathrm{NH}_{2}$ exhibited reverse selectivity for gas pairs $\mathrm{H}_{2} / \mathrm{CO}_{2}$ and $\mathrm{N}_{2} / \mathrm{CH}_{4}$, leading to the following order of gas permeability: $\mathrm{P}_{\mathrm{CO}_{2}}>\mathrm{P}_{\mathrm{H}_{2}}>\mathrm{P}_{\mathrm{O}_{2}}>\mathrm{P}_{\mathrm{CH}_{4}}$ $>\mathrm{P}_{\mathrm{N} 2}$. Reverse selectivity for the gas pairs of $\mathrm{H}_{2} / \mathrm{CO}_{2}$ and $\mathrm{N}_{2} / \mathrm{CH}_{4}$ can be attributed to the higher condensability of the larger gases and has been observed in microporous pol-

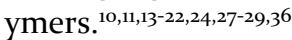

To better understand and rationalize the gas transport properties of CANAL-PIs, we conducted wide-angle X-ray scattering (WAXS). All CANAL-PIs were amorphous and

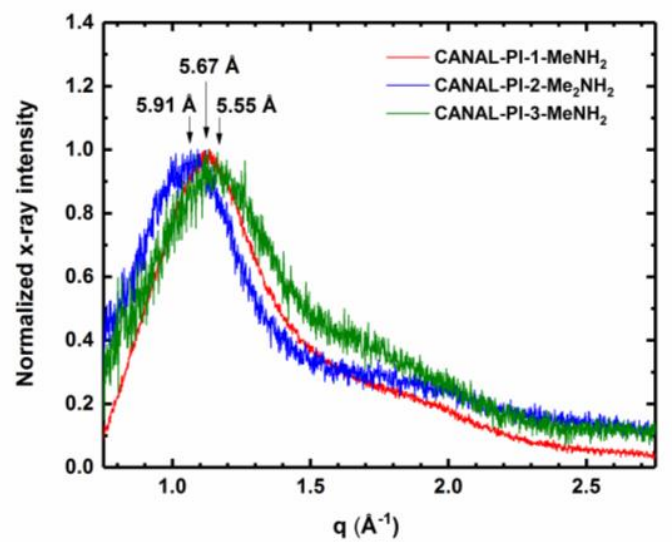

Figure 6. Wide-angle X-ray scattering data (WAXS) of CANAL-PI films.

Table 2. Gas Permeability and Permselectivity of CANAL-PIs $\left(\mathrm{T}=35^{\circ} \mathrm{C} ; 2\right.$ bar)

\begin{tabular}{|c|c|c|c|c|c|c|c|c|c|}
\hline \multirow{2}{*}{ Polymer } & \multicolumn{5}{|c|}{ Permeability (Barrer) } & \multicolumn{4}{|c|}{ Ideal selectivity $(\alpha \mathrm{X} / \mathrm{Y})$} \\
\hline & $\mathrm{H}_{2}$ & $\mathrm{~N}_{2}$ & $\mathrm{O}_{2}$ & $\mathrm{CH}_{4}$ & $\mathrm{CO}_{2}$ & $\mathrm{H}_{2} / \mathrm{N}_{2}$ & $\mathrm{H}_{2} / \mathrm{CH}_{4}$ & $\mathrm{O}_{2} / \mathrm{N}_{2}$ & $\mathrm{CO}_{2} / \mathrm{CH}_{4}$ \\
\hline CANAL-PI-1-MeNH $2,44 \mu \mathrm{m}$ & & & & & & & & & \\
\hline Freshly prepared & 462 & 20.7 & 81 & 16.3 & 419 & 22 & 28 & 3.9 & 26 \\
\hline Aged $73 \mathrm{~d}$ & 425 & 16.6 & 71 & 13.7 & 365 & 25 & 31 & 4.2 & 27 \\
\hline Aged $115 \mathrm{~d}$ & 417 & 16.7 & 69 & 12.9 & 353 & 25 & 32 & 4.1 & 27 \\
\hline CANAL-PI-2-Me ${ }_{2} \mathrm{NH}_{2}, 51 \mu \mathrm{m}$ & & & & & & & & & \\
\hline Freshly prepared & 1154 & 91 & 319 & 108 & 1691 & 13 & 11 & 3.5 & 15 \\
\hline Aged $54 \mathrm{~d}$ & 1120 & 79 & 274 & 89 & 1330 & 14 & 13 & 3.5 & 15 \\
\hline Aged $101 \mathrm{~d}$ & 1060 & 67 & 244 & 72 & 1237 & 16 & 15 & 3.7 & 17 \\
\hline CANAL-PI-3-MeNH $2,45 \mu \mathrm{m}$ & & & & & & & & & \\
\hline Freshly prepared & 282 & 7.0 & 33 & 4.8 & 157 & 40 & 59 & 4.7 & 33 \\
\hline Aged $65 \mathrm{~d}$ & 259 & 5.53 & 25 & 3.6 & 122 & 41 & 64 & 4.7 & 34 \\
\hline
\end{tabular}

\footnotetext{
${ }^{a}$ Measured using the constant-volume/variable-pressure method at 2 bar and $35{ }^{\circ} \mathrm{C} .{ }^{b}$ Calculated from $\alpha_{\mathrm{X} / \mathrm{Y}}=\mathrm{P}_{\mathrm{X}} / \mathrm{P}_{\mathrm{Y}}$.
} 
exhibited a broad scattering feature that peaks around $q=$ 1-1.2 $\AA^{-1}$ in the WAXS patterns, corresponding to intersegmental distances of 5-6 $\AA$ (Figure 6).39-41 The scattering peak of CANAL-PI-2- $\mathrm{Me}_{2} \mathrm{NH}_{2}$ slightly shifted to lower $q$ corresponding to a larger intersegmental distance at $5.9 \AA$, as compared to CANAL-PI-1-MeNH $\mathrm{H}_{2}$ and CANAL-PI-3$\mathrm{MeNH}_{2}$, which showed intersegmental distances at 5.5-5.7 A.

The N2BC motif from CANAL is most similar in structure to Tröger's base (TB) or carbocyclic Tröger's base (CTB) motifs, in that they all have multicyclic rigid cores fused with two outer aromatic rings. While both the TB and CTB motifs are $\mathrm{V}$-shaped with a single contortion site, the $\mathrm{N}_{2} \mathrm{BC}$ motif has a $\mathrm{W}$-shaped conformation with three contortion sites. Direct comparison of the transport properties of analogous PIs synthesized from these molecular ladder motifs can therefore provide insights into how the multicyclic cores affect chain packing of these PIs. CANAL-PI-1$\mathrm{MeNH}_{2}$ and the previously reported 6FDA-CTBDA ${ }^{27}$ (Scheme 2b) consist of the same 6FDA dianhydride and both have one $o$-methyl substituent to the imide linkage. We have treated and measured the membranes of these two PIs under identical conditions, thereby offering valid comparison of their gas permeation property. Interestingly, compared to 6FDA-CTBDA, CANAL-PI-1-MeNH $\mathrm{H}_{2}$ is about $50 \%$ higher in permeability for $\mathrm{CO}_{2}$ with similar selectivity. Comparing the PIs from $\mathrm{N}_{2} \mathrm{BC}$ and $\mathrm{TB}$ motifs with two o-methyl substituents, CANAL-PI-2- $\mathrm{Me}_{2} \mathrm{NH}_{2}$ has similar $\mathrm{CO}_{2}$ permeability and $\mathrm{CO}_{2} / \mathrm{CH}_{4}$ selectivity to that of 6FDA-4MTBDA ${ }^{28}$ (Scheme 2b). Overall, CANAL-PIs are closer to the $2008 \mathrm{CO}_{2} / \mathrm{CH}_{4}$ Robeson upper bound ${ }^{42}$ than commercial PIs and PIM-PIs containing triptycene, TB, and CTB motifs (Figure 7). Notably, CANAL-PI-3-MeNH has similar ideal $\mathrm{CO}_{2} / \mathrm{CH}_{4}$ permselectivity as commercial polymers such as Matrimid, but is almost two orders of magnitude more permeable. This makes the CANAL motif a promising building block for the development of polymeric membrane materials for gas separation.

The aging process of the CANAL-PI membranes was tracked by their gas permeability over time. Physical aging is a phenomenon observed in highly glassy polymers whose specific volume and other bulk properties are out of equilibrium. In the physical aging process, the specific volume of the polymer glass slowly approaches equilibrium. In the context of gas separation membranes, the decrease in fractional free volume during aging leads to decrease in permeability and often concomitant increase in selectivity. When directly comparing the aging of two polymers, it is imperative that their thickness, permeability for freshly prepared membranes, and the pretest treatment are all similar. Thin polymer films and polymers with extremely high fresh permeability are known to age relatively fast.4345 Pretest treatments can dramatically affect the fresh permeability of a polymer membrane and therefore its aging. With these precautions in mind, we compared aging of CANAL-PIs with other PIM-PIs that Pinnau and coworkers have previously studied under identical conditions. Table

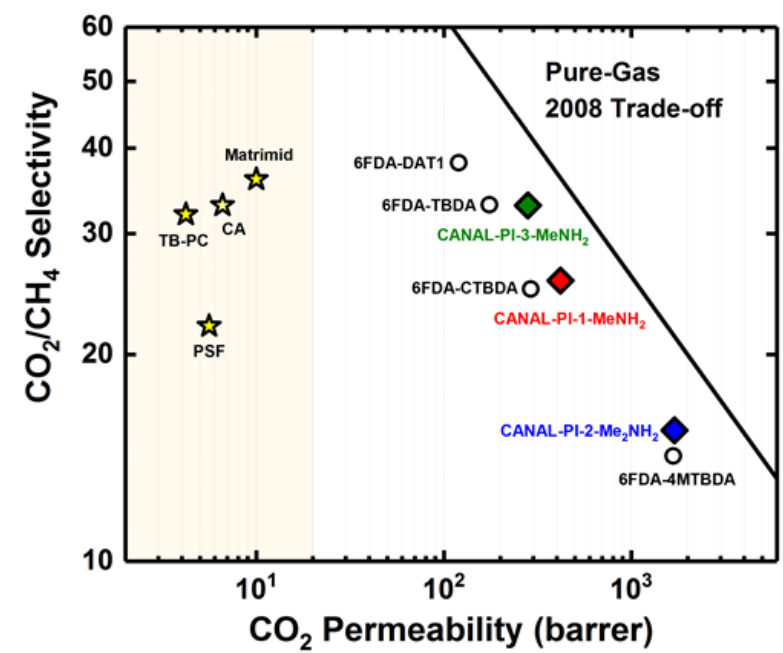

Figure 7. CANAL-PIs, other PIM-PIs (6FDA-DAT1 ${ }^{12}$, 6FDA-TBDA ${ }^{27}$, 6FDA-CTBDA ${ }^{27}$, and 6FDA-4MTBDA ${ }^{28}$ ) and commercial polymers (TB-PC, Matrimid, cellulose acetate (CA), polysulfone (PSF)) relative to the $2008^{42}$ $\mathrm{CO}_{2} / \mathrm{CH}_{4}$ permeability/selectivity upper bound.

S6 summarizes the changes in permeability and permselectivity during aging for these PI membranes with similar thicknesses and identical pretest treatment (soaking in methanol followed by heating at $120^{\circ} \mathrm{C}$ for $24 \mathrm{~h}$ ). Notably, CANAL-PIs exhibited lesser extent of aging than PIs consisting of $\mathrm{CTB},{ }^{25}$ but similar to PIs containing triptycene motifs. ${ }^{12}$ The $\mathrm{O}_{2}$ permeability of CANAL-PI-1-MeNH $\mathrm{H}_{2}$ decreased by only $15 \%$ in 115 days, whereas that of 6FDACTBDA with CTB repeat units decreased $23 \%$ after only 60 days. The $\mathrm{O}_{2}$ permeability of 6FDA-DAT1 (Scheme $2 \mathrm{~b}$ ) with triptycene repeat units also decreased by $15 \%$ after 150 days, but its $\mathrm{O}_{2}$ permeability for a freshly prepared membrane was less than $30 \%$ of that of CANAL-PI-2-MeNH

The comparisons of permeation properties and physical aging demonstrated considerable promise of the CANALtype ladder motifs as building blocks for microporous polymer membranes.

\section{CONCLUSIONS}

We report the facile synthesis of a series of laddershaped diamines via one-step CANAL reaction, which were then used to prepare soluble microporous PIs. The 6FDAbased CANAL-PIs exhibited excellent thermal stability and high BET surface areas that are comparable to our previously reported CANAL ladder polymers. $O$-methyl substituents around the imide linkage were used to modulate the surface area, microporosity, and thus the gas transport properties of the CANAL-PIs. High permeabilities and moderate selectivities of industrially important gases were obtained from mechanically robust CANAL-PI membranes. These CANAL-PI membranes also exhibited relatively slow aging.

Facile synthesis, mechanically robust membranes, and good gas transport properties of CANAL-PIs make them 
promising materials for membrane gas separations. We envision the expansion to a broad range of ladder-shaped building blocks via straightforward and efficient CANAL reactions for the development of soluble microporous polymers for important gas separations.

\section{ASSOCIATED CONTENT}

Supporting Information. This material is available free of charge via the Internet at http://pubs.acs.org.

Experimental procedure, crystallographic data, simulation procedure, CANAL reaction mechanism, NMR spectra, FT-IR spectra, TGA traces, stress-strain curves, permeability/selectivity trade-off plots, diffusion and solubility coefficients of CANAL-PI's, and aging data of PIMPI's.

\section{AUTHOR INFORMATION}

\section{Corresponding Authors}

*E-mails: yanx@stanford.edu; ingo.pinnau@kaust.edu.sa

\section{Author Contributions}

TThese authors contributed equally.

\section{ACKNOWLEDGMENTS}

We thank U.S. Army Research Office (W911NF-16-1-0018 to Y. Xia), the Donors of the American Chemical Society Petroleum Research Fund (56820-DN17 to Y. Xia), the Semiconductor Research Corporation, seed funding from the Stanford Natural Gas Initiative, and the King Abdullah University of Science and Technology (BAS/1/1323-O1-o1 to I. Pinnau) for supporting of this research. Single-crystal X-ray diffraction experiments were performed at beamline 11.3.1 at the Advanced Light Source (ALS). The ALS is supported by the Director, Office of Science, Office of Basic Energy Sciences, of the U.S. Department of Energy under contract no. DE-ACo2-05CH11231. H. W. H. Lai thanks the National Science Foundation for the Graduate Research Fellowship (DGE- 156518) and the Stanford Office of the Provost for Graduate Education for the EDGE-STEM fellowship. Y. C. Teo was supported by an A*STAR graduate fellowship.

\section{REFERENCES}

(1) McKeown, N. B.; Budd, P. M. Exploitation of intrinsic microporosity in polymer-based materials. Macromolecules 2010, 43, 5163-5176.

(2) Yampolskii, Y. Polymeric gas separation membranes. Macromolecules 2012, 45, 3298-3311.

(3) Sanders, D. F.; Smith, Z. P.; Guo, R.; Robeson, L. M.; McGrath, J. E.; Paul, D. R.; Freeman, B. D. Energy-efficient polymeric gas separation membranes for a sustainable future: a review. Polymer 2013, 54, 4729-4761.

(4) Baker, R. W.; Low, B. T. Gas separation membrane materials: a perspective. Macromolecules 2014, 47, 6999-7013.

(5) H. B. Park, J. Kamcev, L. M. Robeson, M. Elimelech, and B. D. Freeman, Science 2017, 356, 1137.

(6) Koros, W. J.; Zhang, C. Materials for next-generation molecularly selective synthetic membranes. Nat. Mater. 2017, 16, 289-297. (7) Mckeown, N. B. The synthesis of polymers of intrinsic microporosity (PIMs). Sci. China Chem. 2017, 6o, 1023-1032.
(8) Teo, Y. C.; Lai, H. W. H.; Xia, Y. Synthesis of ladder polymers: developments, challenges, and opportunities. Chem. Eur. J. 2017, 23, 14101-14112.

(9) Kim, S.; Lee, Y. M. Rigid and microporous polymers for gas separation membranes. Prog. Polym. Sci. 2015, 43, 1-32.

(10) Carta, M.; Croad, M.; Malpass-Evans, R.; Jansen, J. C.; Bernardo, P.; Clarizia, G.; Friess, K.; Lanc, M.; McKeown, N. B. Triptycene induced enhancement of membrane gas selectivity for microporous Tröger's base polymers. Adv. Mater. 2014, 26, 3526-3531. (11) Rose, I.; Carta, M.; Malpass-Evans, R.; Ferrari, M.-C.; Bernardo, P.; Clarizia, G.; Jansen, J. C.; McKeown N. B.; Highly permeable benzotriptycene-based polymer of intrinsic microporosity. ACS Macro Lett. 2015, 4, 912-915.

(12) Alghunaimi, F.; Ghanem, B.; Alaslai, N.; Swaidan, R.; Litwiller, E.; Pinnau, I. Gas permeation and physical aging properties of iptycene diamine-based microporous polyimides. J. Membr. Sci. 2015, 490, 321-327.

(13) Ghanem, B. S.; Alghunaimi, F.; Ma, X.; Alaskai, N.; Pinnau, I. Synthesis and characterization of novel triptycene dianhydrides and polyimides of intrinsic microporosity based on 3,3'-dimethylnaphthidine. Polymer 2016, 101, 225-232.

(14) Ghanem, B. S.; Swaidan, R.; Ma, X.; Litwiller, E.; Pinnau, I. Energy-efficient hydrogen separation by AB-type ladder-polymer molecular sieves. Adv. Mater. 2014, 26, 6696-67oo.

(15) Ghanem, B. S; Swaidan, R.; Litwiller, E.; Pinnau, I. Ultra-microporous triptycene-based polyimide membranes for high-performance gas separation. Adv. Mater. 2014, 26, 3688-3692.

(16) Ghanem, B. S.; Alghunaimi, F.; Wang, Y.; Genduso, G.; Pinnau, $P$. Synthesis of highly gas-permeable polyimides of intrinsic microporosity derived from 1,3,6,8-tetramethyl-2,7-diaminotriptycene. ACS Omega 2018, 3, 11874-11882.

(17) Luo, S.; Zhang, Q.; Zhu, L.; Lin, H.; Kazanowska, B. A.; Doherty, C. M.; Hill, A. J.; Gao, P.; Guo, R. Highly selective and permeable microporous polymer membranes for hydrogen and $\mathrm{CO}_{2}$ removal from natural gas. Chem. Mater. 2018, 30, 5322-5332. (18) Budd, P. M.; Msayub, K. J.; Tattershall, C. E.; Ghanem, B. S.; Reynolds, K. J.; McKeown, N. B. Gas separation membranes from polymers of intrinsic microporosity. J. Membr. Sci. 2005, 251, 263269

(19) Ghanem, B. S.; McKeown, N. B.; Budd, P. M.; Selbie, J. D.; Fritsch, D. High-performance membranes from polyimides with intrinsic microporosity. Adv. Mater. 2008, 20, 2766-2771.

(20) Carta, M.; Malpass-Evans, R.; Croad, M.; Rogan, Y.; Jansen, J. C.; Bernardo, P.; Bazzarelli, F.; McKeown, N. B. An Efficient polymer molecular sieve for membrane gas separations. Science 2013, 339, 303-307.

(21) Rogan, Y.; Starannikova, L.; Ryzhikh, V.; Yampolskii, Y.; Bernardo, P.; Bazzarelli, F.; Jansen, J. C.; McKeown, N. B. Synthesis and gas permeation properties of novel spirobisindane-based polyimides of intrinsic microporosity. Polym. Chem. 2013, 4, 38133820.

(22) Bezzu, C. G.; Carta, M.; Tonkins, A.; Jansen, J. C.; Bermardo, P.; Bazzarelli, F.; McKeown, N. B. A spirobifluorene-based polymer of intrinsic microporosity with improved performance for gas separation. Adv. Mater. 2012, 24, 5930-5933.

(23) Ma, X.; Salinas, O.; Litwiller, E.; Pinnau, I. Novel spirobifluorene- and dibromospirobifluorene-based polyimides of intrinsic microporosity for gas separation applications. Macromolecules 2013, 46, 9618-9624.

(24) Ma, X.; Ghanem, B.; Salines, O.; Litwiller, E.; Pinnau, I. Synthesis and effect of physical aging on gas transport properties of a microporous polyimide derived from a novel spirobifluorenebased dianhydride. ACS Macro Lett. 2015, 4, 231-235.

(25) Bezzu, C. G.; Carta, M.; Ferrari, M.-C.; Jansen, J. C.; Monteleone, M.; Esposito, E.; Fuoco, A.; Hart, K.; Liyana-Arachchi, T. P.; Colina, C. M.; McKeown, N. B. The synthesis, chain-packing sim- 
ulation and long-term gas permeability of highly selective spirobifluorene-based polymers of intrinsic microporosity J. Mater. Chem. A 2018, 6, 10507-10514.

(26) Zhuang, Y.; Seong, J. G.; Do, Y. S.; Jo, H. J.; Cui, Z.; Lee, J.; Lee, Y. M.; Guiver, M. D. Intrinsically microporous soluble polyimides incorporating Tröger's base for membrane gas separation. Macromolecules 2014, 47, 3254-3262.

(27) Abdulhamid, M. A.; Ma, X.; Miao, X.; Pinnau, I. Synthesis and characterization of a microporous 6FDA-polyimide made from a novel carbocyclic pseudo Tröger's base diamine: effect of bicyclic bridge on gas transport properties. Polymer 2017, 130, 182-19o.

(28) Lee, M.; Bezzu, C. G.; Carta, M.; Bernardo, P.; Clarizia, G.; Jansen, J. C.; McKeown, N. B. Enhancing the gas permeability of Tröger's base derived polyimides of intrinsic microporosity. Macromolecules 2016, 490, 4147-4154.

(29) Ma, X.; Abdulhamid, M. A.; Pinnau, I. Design and synthesis of polyimides based on carbocyclic pseudo-Tröger's base-derived dianhydrides for membrane gas separation applications. Macromolecules 2017, 50, 5850-5857.

(30) Williams, R.; Burt, L. A.; Esposito, E.; Jansen, J. C.; Tocci, E.; Rizzuto, C.; Lanč, M.; Carta, M.; McKeown, N. B. A highly rigid and gas selective methanopentacene-based polymer of intrinsic microporosity derived from Tröger's base polymerization. J. Mater. Chem. A 2018, 6, 5661-5667.

(31) Liu, S.; Jin, Z.; Teo, Y. C.; Xia, Y. Efficient synthesis of rigid ladder polymers via palladium catalyzed annulation. J. Am. Chem. Soc. 2014, 136, 17434-17437.

(32) Lai, H. W. H.; Liu, S.; Xia, Y. Norbornyl benzocyclobutene ladder polymers: conformation and microporosity. J. Polym. Sci. Part A Polym. Chem. 2017, 55, 3075-3081.

(33) Lai, H. W. H.; Teo, Y. C.; Xia, Y. Functionalized rigid ladder polymers from catalytic arene-norbornene annulation polymerization. ACS Macro Lett. 2017, 6, 1357-1361.

(34) Hoehn, H. H.; Richter, J. W. US Patent 3,899,309, 1975.
(35) Kim, T. H.; Koros, W. J.; Husk, G. R.; O'Brien, J. C. Relationship between gas separation properties and chemical structure in a series of aromatic polyimides. J. Membr. Sci. 1988, 37, 45-62.

(36) Tanaka, K.; Okano, M.; Toshino, H.; Kita, H.; Okamoto, K.-I. Effect of methyl substituents on permeability and permselectivity of gases in polyimides prepared from methyl-substituted phenylenediamines. J. Polym. Sci. Polym. Phys. 1992, 30, 907-914. (37) Catellani, M.; Ferioli, L. An improved synthesis of 1,4-cis,exohexa- or tetrahydromethano- or ethanobiphenylene derivatives catalyzed by palladium complexes. Synthesis 1996, 6, 769-772.

(38) Chai, D. I.; Thansandote, P.; Lautens, M. Mechanistic studies of $\mathrm{Pd}$-catalyzed regioselective aryl $\mathrm{C}-\mathrm{H}$ bond functionalization with strained alkenes: origin of regioselectivity. Chem. Eur. J. 2011, 17, 8175-8188.

(39) Ritter, N.; Antonietti, M.; Thomas, A.; Senkovska, I.; Kaskel, S.; Weber, J. Binapthalene-based soluble polyimides: the limits of intrinsic microporosity. Macromolecules 2009, 42, 8017-8020.

(40) McDermott, A. G.; Larsen, G. S.; Budd, P. M.; Colina, C. M.; Runt, J. Structural characterization of a polymer of intrinsic microporosity: X-ray scattering with interpretation enhanced by molecular dynamics simulations. Macromolecules 2011, 44, 14-16. (41) McDermott, A. G.; Budd, P. M.; McKeown, N. B.; Colina, C. M.; Runt, J. Physical aging of polymers of intrinsic microporosity: a SAXS/WAXS study. J. Mater. Chem. A. 2014, 2, 11742-11752. (42) Roberson, L. M. The upper bound revisited. J. Membr. Sci. 2008, 320, 390-400.

(43) Huang, Y.; Paul, D. R. Effect of film thickness on the gas-permeation characteristics of glassy polymer membranes. Ind. Eng. Chem. Res. 2007, 46, 2342-2347.

(44) Ma, X.; Pinnau, I. Effect of film thickness and physical aging on "intrinsic" gas permeation properties of microporous ethanoanthracene-based polyimides. Macromolecules 2018, 51, 10691076.

(45) Tiwari, R. R.; Jin, J.; Freeman, B. D.; Paul, D. R. Physical aging, $\mathrm{CO}_{2}$ sorption and plasticization in thin films of polymer with intrinsic microporosity (PIM-1). J. Membr. Sci. 2017, 537, 362-371.

\section{Insert Table of Contents artwork here}

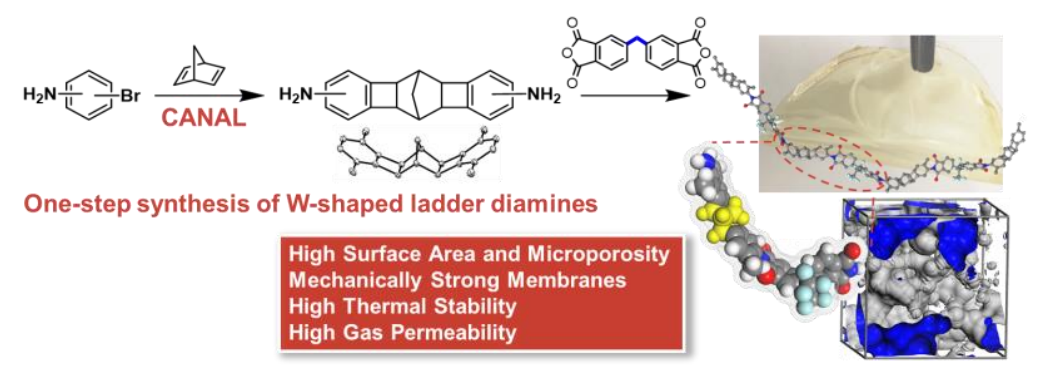

